\title{
Prediction models of mechanical properties for pet-mortar composite in sodium sulphateaggressive mediums
}

\author{
Nabil Kazi Tani ${ }^{1,4}$, A.S. Benosman ${ }^{1,2,3}$, Y. Senhadji ${ }^{3}$, H. Taïbi ${ }^{2}$, M. Mouli ${ }^{3}$, M. Belbachir ${ }^{2}$ \\ ${ }^{1}$ Higher School of Applied Sciences (ESSAT), BP 165, 13000 BelHorizon, Tlemcen, Algeria. \\ ${ }^{2}$ Faculty of Exact and Applied Sciences, Laboratory of Polymer Chemistry LCP, University of Oran 1, \\ Ahmed Benbella, Oran, Algeria. \\ ${ }^{3}$ Department of Civil Engineering, LABMAT, ENPO Maurice Audin, Oran, Algeria. \\ ${ }^{4}$ LCGE Laboratory, Faculty of Mechanical Engineering, USTO-MB, Oran, Algeria.
}

\begin{abstract}
In this research, an investigation was carried out on the effect of sodium sulphate attack on the durability of composites produced with waste polyethylene terephthalate (PET). Experiments were accomplished on limestone sand and cement mortars where the blended Portland cement was partially replaced by various volume fractions of waste PET particles $(6 \%, 12 \%$ and 17\%). The test solutions used to supply the sulphate ions and cations were 5\%sodium sulphate solution. Compressive strengths measured on specimens were used to assess the changes in the mechanical properties of PET-mortars exposed to sulphate attack at different ages, mainly the Young modulus of elasticity. Based on experimental compressive tests on PETMortar composite specimens and there densities, the evolution of Young modulus of elasticity has been analyzed in accordance with normative models given by (ACI-318) and (BS-8110) codes of practice. In addition, a comparative study has been carried out for corrosion resistance coefficients $\mathrm{K}$ of unmodified mortar to those modified with waste PET particles. It can be noticed that, for the composite immersed in a corrosive $\mathrm{Na}_{2} \mathrm{SO}_{4}$ solution, the corrosion resistance coefficients decrease with the increase of the immersion period. The corrosion sulphate resistance $\mathrm{K}$ based on Young modulus before and after immersion of PET-mortar composites is better than that of the control mortar. Therefore, for safety considerations of PET-mortar composites use, ACI 318 is recommended code for design and investigation works. Also, it can be concluded that adding waste PET by volume fractions $(6 \%, 12 \%$ and 17\%) to blend Portland cement renders this cement more resistant to the sodium sulphate aggressive medium. Therefore, composites materials based waste PET are often presented as the materials of the future because of their potential for innovation and the advantages they offer. In fact, using waste PET as cement substitutes reduces the energy consumption. These modified mortars address problems related to environmental pollution by $\mathrm{CO}_{2}$ emissions, and are used to repair various reinforced concrete structures in sodium sulphate aggressive mediums.
\end{abstract}

\section{Introduction}

In the last couple years, waste polyethylene terephthalate (PET) is produced within large amount by plastic industry in all over the world [1] andsince PET waste is not biodegradable, it can remain in nature for hundreds of years and causes too many environmental problems.

Various studies [2-6] have been developed so far in order to find ecologic and green ways to dispose of plastics wastes, one of the main solutions proposed by researchers is to incorporate waste PET in building materials technology in order to substitute volumetric amount of cement [7] and/or aggregates [8-10] in concrete and mortars mix-design.

In this research, an investigation was carried out on the effect of sodium sulphate attacks on the durability of composites produced with waste polyethylene terephthalate (PET). Experiments were accomplished on limestone sand and cement mortars where the blended Portland cement was partially replaced by various volume fractions of waste PET particles $(6 \%, 12 \%$ and 17 $\%)$.

Test solutions used to supply the sulphate ions and cationswere $5 \% \mathrm{Na}_{2} \mathrm{SO}_{4}$ solution. Tap water was used as the reference solution. Compressive strengths measured on specimens were used to assess the changes in the mechanical properties of PET-mortars exposed to sodium sulphate attacks at different ages, mainly the Young modulus of elasticity.After compression testing, X-ray diffraction was conducted on some selected surface fractures to investigate microstructural nature of the sulphate attacks. 


\section{Raw materials}

\subsection{Cement}

The cement used was a blended Portland cement type CPJ-CEM II/A42.5 supplied by Zahana factory, located in western Algeria, with $1022 \mathrm{~kg} / \mathrm{m}^{3}$ bulk density; its compressive strength at 28 days was $42.5 \mathrm{MPa}$. The absolute density of the cement used was $3.15 \mathrm{~g} / \mathrm{cm}^{3}$ and its specific surface area measured with the Blaine method was $3532 \mathrm{~cm}^{2} / \mathrm{g}$. Its initial and final setting times were 170 and $245 \mathrm{~min}$, respectively. Mineralogical and chemical compositions of cement are listed in Table 1.The chemical composition was obtained using an X-ray fluorescence spectrometer.

Table 1.Chemical and mineralogical compositions of cement (wt.\%)

\begin{tabular}{|c|c|c|}
\hline \multirow{10}{*}{ 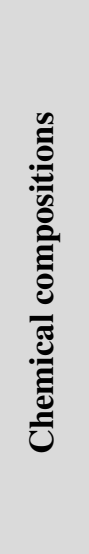 } & $\mathrm{SiO}_{2}$ & 20.91 \\
\hline & $\mathrm{Al}_{2} \mathrm{O}_{3}$ & 5.52 \\
\hline & $\mathrm{Fe}_{2} \mathrm{O}_{3}$ & 3.56 \\
\hline & $\mathrm{CaO}$ & 63.50 \\
\hline & $\mathrm{MgO}$ & 0.64 \\
\hline & $\mathrm{SO}_{3}$ & 2.79 \\
\hline & $\mathrm{K}_{2} \mathrm{O}$ & 1.23 \\
\hline & $\mathrm{Na}_{2} \mathrm{O}$ & 0.13 \\
\hline & $\mathrm{CaO}$ free & 2.35 \\
\hline & LOI & 1.19 \\
\hline \multirow{4}{*}{ 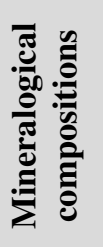 } & $\mathrm{C}_{3} \mathrm{~S}$ & 49.39 \\
\hline & $\mathrm{C}_{2} \mathrm{~S}$ & 22.97 \\
\hline & $\mathrm{C}_{3} \mathrm{~A}$ & 8.61 \\
\hline & $\mathrm{C}_{4} \mathrm{AF}$ & 10.83 \\
\hline
\end{tabular}

\subsection{Sand}

The crushed natural limestone sand was obtained from the quarry of Kristel, in Oran, West Algeria. The maximum size of sand grains was $5 \mathrm{~mm}$. The absolute density and absorption coefficient of crushed sand were $2.53 \mathrm{~g} / \mathrm{cm}^{3}$ and $0.5 \%$, respectively. The grading of crushed sand is presented in Table 2, according to standard NF P18-560 [11].

\subsection{Waste Polyethylene Terephthalate}

Waste PET bottle granules (PET) used as particles were supplied by TRAMAPLAST PET Bottle Plant, in Tlemcen, Algeria. These particles were obtained by collecting the waste PET bottles and washing them; they are then crushed by granules into machines. In addition, they have an irregular shape and a rough texture surface, which enables the adherence of the particle-matrix. The bulk density of the waste PET particles used was $401.4 \mathrm{~kg} / \mathrm{m}^{3}$.

After preliminary tests, waste PET particles of size lower than $1 \mathrm{~mm}$ were used in this study. The sieve analysis of waste PET particles was carried out according to standard NF P18-560 [11] and is presented in Table 2.

Table 2. Sieve analysis of waste PET-particles and crushed limestone sand.

\begin{tabular}{|c|c|c|}
\hline Sieve size (mm) & \multicolumn{2}{|c|}{ Cumulative passing (\%) } \\
\hline & Waste PET & Sand \\
\hline 5 & 99.92 & 99.83 \\
\hline 2.5 & 98.16 & 98.37 \\
\hline 1.25 & 96.82 & 65.37 \\
\hline 0.63 & 55.78 & 38.3 \\
\hline 0.315 & 35.48 & 19.07 \\
\hline 0.16 & 18.28 & 8.20 \\
\hline 0.125 & 9.56 & 3.325 \\
\hline
\end{tabular}

\section{Composite mixing conditions}

The mortar manufactured without waste PET particles was first optimized on the basis of its mechanical criteria and was then used as a reference composite. The composites containing waste PET particles were produced in accordance with the results of the works of Benosman et al. [12]. A massic ratio of 3 between sand (S) and cement (C) was respected. Four different mixtures were prepared (the control mixtures without plastic waste and three PET\# mixtures including 6\%, $12 \%$ and $17 \%$ waste PET particles by volume).Mixture name of the different composites were: PET0 (without plastic waste), PET6, PET12 and PET17. The water to binder ratio was kept constant at 0.5 . So, after pouring fresh material into the molds(EN 196-1), the samples were stored in a room where hygrometry and temperature were controlled for $24 \mathrm{~h}$ (98\% relative humidity, and $20 \pm$ $\left.1{ }^{\circ} \mathrm{C}\right)$. After removal from the molds, at 1 day of age, mortar specimens were cured in saturated lime water at $20 \pm 1{ }^{\circ} \mathrm{C}$, until the time of testing.

\section{Test methods of resistance to sodium sulphate attack}

The mortar specimens were cured in water saturated with lime at $20 \pm 1^{\circ} \mathrm{C}$ for 28 days before being exposed to sulphate attack. Three specimens of each mortar and composite mixes $\left(40 \times 40 \times 160 \mathrm{~mm}^{3}\right)$ were immersed in two types of solutions: distilled water (reference medium) and 5\% sodium sulphate solution, Figure 1. According to the standard ASTM C1012-04 [13], the pH of the sulphate solution should be between 6 and 8 and the solution must be renewed each week, which requires huge amounts of sodium sulphate.

For this, Mehta's [14] method and that of Siad et al. [15] were adopted; they all recommend the control of the $\mathrm{pH}$ within a range of 6.0-8.0 by adding a suitable amount of sulfuric acid solution $\left(0.1 \mathrm{~N} \mathrm{H}_{2} \mathrm{SO}_{4}\right)$, figure 2 . 


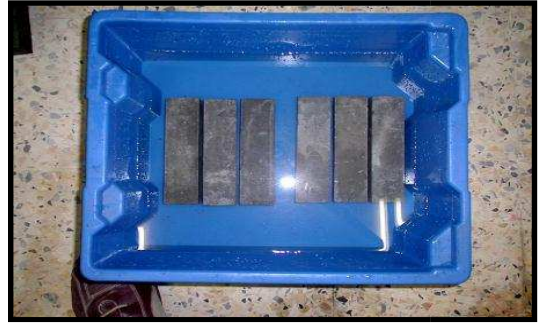

Fig. 1. Immersion of the specimens in the aggressive solution

The correction is performed daily during the first weeks of immersion, and then becomes weekly, for the rest of the test. In addition, the aggressive solutions were totally renewed each 12 weeks.

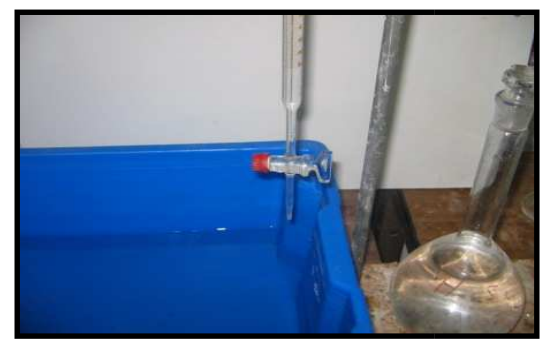

Fig. 2. Correction of the sulphate solution by adding small quantities of $0.1 \mathrm{~N} \mathrm{H}_{2} \mathrm{SO}_{4}$, up to a pH equal to 6-8.

After immersion in sodium sulphate solution $\left(\mathrm{Na}_{2} \mathrm{SO}_{4}\right)$ for the required period of time, ASTM C101204 [13], the specimens were tested for residual mechanical properties. The Young modulus loss (YML\%) is calculated as follows:

$\operatorname{YML}(\%)=\frac{E_{c r}-E_{c s}}{E_{c r}} \times 100(1)$

where $E_{c r}$ is the Young modulus of the specimens before immersion $(\mathrm{MPa})$ and $E_{c s}$ is the average Young modulus of the specimens after immersion in sodium sulphate solutions for the required period of time (180 days).

\section{Results and discussion}

\subsection{Prediction models of mechanical properties}

The static modulus of elasticity E (Young Modulus) represents the one of the most important mechanical characteristics of construction materials (concrete, reinforced concrete, mortars, composites.etc.). This intrinsic property is considering as the basic parameter for the computing strain-stresses in construction structures.

Various countries have been established their design codes based on this empirical relationship between static modulus of elasticity $\mathrm{E}$, and compressive strength of plain concrete at 28 days of curing. The ACI code (ACI318) [16] defines the relationship between elastic modulus of concrete and compressive strength as:

$E=w^{1.5} \cdot 0.043 \cdot \sqrt{f_{c}}(2)$
The British Code of practice (BS-8110) [17] recommends the following expression for static modulus of elasticity with cube compressive strength of concrete as:

$E=w^{2} \cdot 0.0017 \cdot f_{c}^{0.33}(3)$

where, Ec: The static modulus of elasticity (E) at 28 days in $\mathrm{MPa}$

fc : Compressive strength at 28 days, in $\mathrm{MPa}$

$\mathrm{w}$ : Air dry density of mortar

Based on experimental compressive tests on PETmortar composite specimens [18], and there densities, graphs in (figures 3,4) bellow show the evolution of Young modulus evaluated by empirical relationships in accordance to (ACI-318) and (BS-8110) codes [16,17].

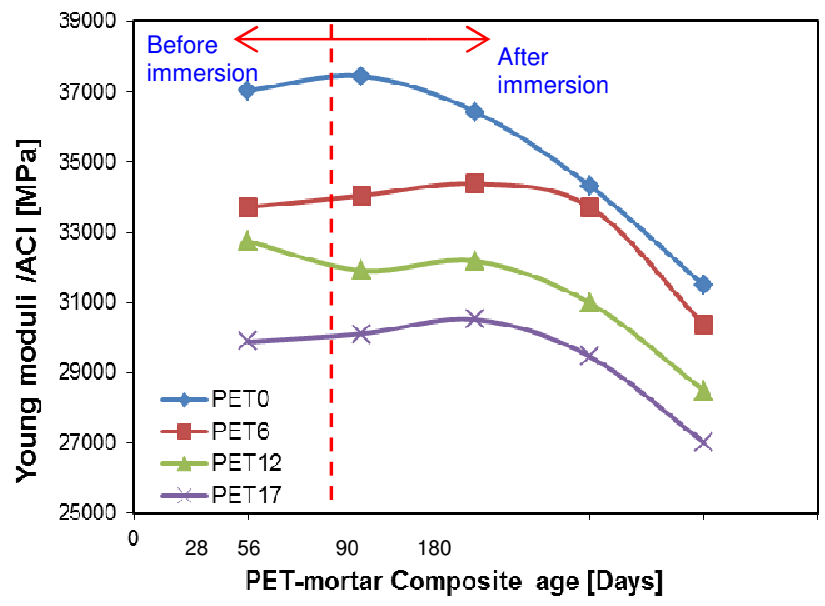

Fig. 3.Evolution of Young modulus with volumetric waste PET rate and composite mortar ages via ACI-318 code before and after $5 \%$ sodium sulphate attacks.

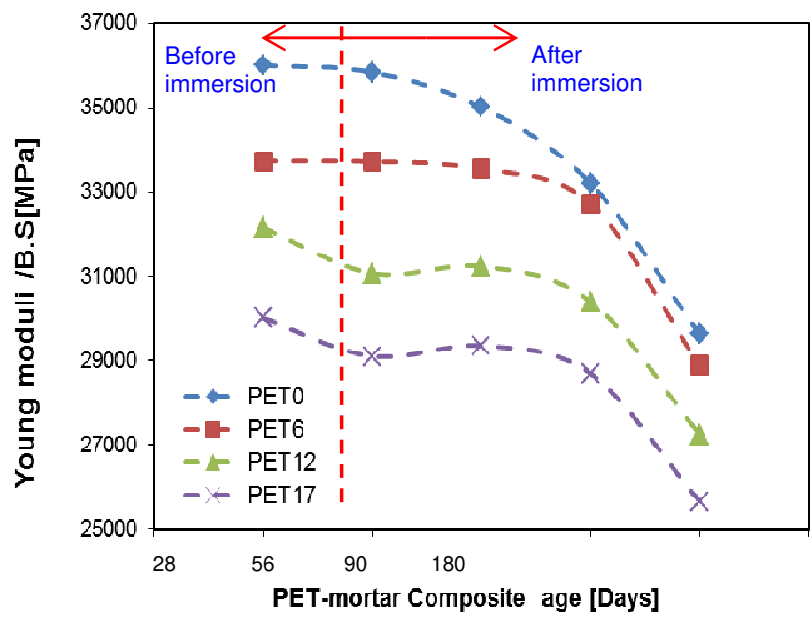

Fig. 4. Evolution of Young modulus with volumetric waste PET rate and composite mortar ages via BS- 8110 code before and after $5 \%$ sodium sulphate attacks.

In the other hand, Young modulus loss ratios have been studied for several volumetric waste PET rates and for each model of predicted codes. The results of the Young modulus loss using the specimens immersed in $5 \% \quad \mathrm{~N}_{2} \mathrm{SO}_{4}$ solutions (figure5) showed that there are variations in time and group. However, a decrease in 
Young Modulus values of all specimens was observed when Young Modulus of elasticity is computed via ACI318 model. However, the rate of increase varied slightly within the group.

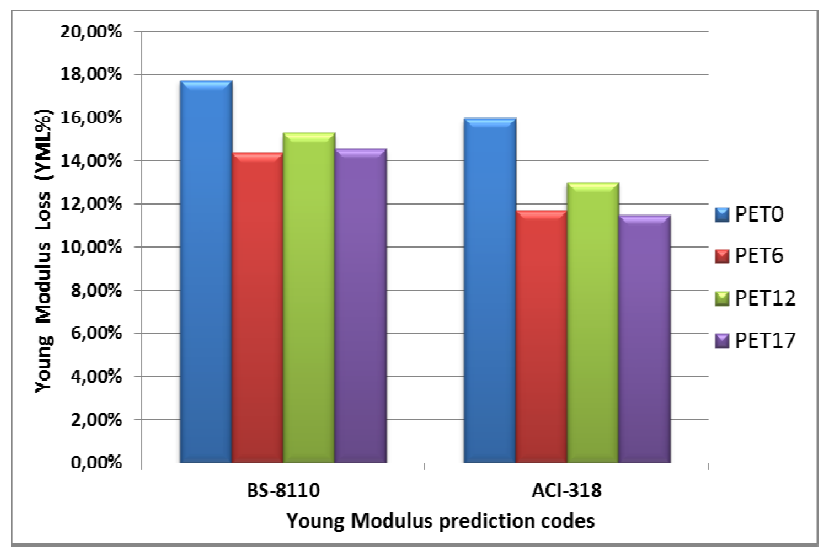

Fig. 5.Young modulus loss $(Y M L \%)$ with volumetric waste PET rate and prediction codes (BS-8110 \& ACI-318) before and after $5 \% \mathrm{Na}_{2} \mathrm{SO}_{4}$ immersion.

It was expected that the mechanical properties loss $(Y M L \%)$ values of modified mortars with waste PET plastic particles would be lower than those of unmodified mortar PET0, by $14.35 \%, 15.28 \%$ and $14.53 \%$ for PET6, PET12 and PET17, respectively for the case where the prediction model is BS-8110 and respectively by $11.72 \%$, $13.01 \%$ and $11.51 \%$ when Young Modulus of elasticity is computed via ACI-318 model. It can therefore be concluded that modified mortars by waste PET plastic particles are resistant to the sodium sulphate aggressive mediums conditions often encountered in the field.

Similarly to experimental results obtained by some previous studies $[19,20]$ in similar fields, it can be stated that, mortar blended within waste polymer particles present a better and promising composite material in building repair against sulphate aggressive mediums $\left(\mathrm{Na}_{2} \mathrm{SO}_{4}, \mathrm{MgSO}_{4}\right)$.

\subsection{Corrosion sodium sulphate resistance}

Furthermore, to compare, effectively, the corrosion resistance coefficients $\mathrm{K}$ of unmodified mortar (Eq. 4) to those modified with PET particles, as it was used by Benosman et al. [12] and Jiang et al. [21]:

$$
K=E c i /{ }_{E C S}(4)
$$

Where $E_{c i}$ is the Young modulus of composite mortars immersed in corrosive $\mathrm{Na}_{2} \mathrm{SO}_{4}$ solutions, $E_{c s}$ the Young modulus of the normally cured composite mortars. The corrosion resistance coefficients of the specimens with and without waste PETplastic are given in Table 3.

It can be seen from table 3 that, for the composite immersed in a corrosive $\mathrm{Na}_{2} \mathrm{SO}_{4}$ solution, the corrosion resistance coefficients decrease with the increase of the immersion period. The corrosion sulphate resistance $\mathrm{K}$ based on Young modulus before and after immersion of PET-mortar composites is better than that of the control mortar (PET0).
Table 3.Corrosion resistance coefficients of PET-mortar composites in $5 \% \mathrm{Na}_{2} \mathrm{SO}_{4}$

\begin{tabular}{|l|c|c|c|c|}
\hline \multirow{2}{*}{$\begin{array}{c}\text { Sodium } \\
\text { sulphateattacks }\end{array}$} & \multicolumn{2}{c|}{ K (BS.8110) } & \multicolumn{2}{c|}{ K (ACI.318) } \\
\cline { 2 - 5 } & 90 days & $\mathbf{1 8 0}$ days & 90 days & $\mathbf{1 8 0}$ days \\
\hline PET0 & 0.922 & 0.823 & 0.927 & 0.850 \\
\hline PET6 & 0.970 & 0.856 & 1.000 & 0.900 \\
\hline PET12 & 0.945 & 0.847 & 0.946 & 0.870 \\
\hline PET17 & 0.956 & 0.855 & 0.986 & 0.904 \\
\hline
\end{tabular}

For all studied cases, corrosion resistance coefficients $\mathrm{K}$ computed via BS.8118 code of practice are lower than the ones computed by ACI 318 model. Therefore, for safety considerations of PET-mortar composites use, ACI 318 is recommended code for design and investigation works. It can be concluded that adding waste PET by volume fractions $(6 \%, 12 \%$ and $17 \%)$ to blended Portland cement renders this cement more resistant to the sodium sulphate aggressive medium. It is evident that the resistance of cement to sulphate aggression is also related to its content in $\mathrm{C}_{3} \mathrm{~A}[22]$.

Therefore, composites materials based waste PET are often presented as the materials of the future because of their potential for innovation and the advantages they offer. In fact, using waste PET as cement substitutes reduces the energy consumption. These PET-modified mortars address problems related to environmental pollution by $\mathrm{CO}_{2}$ emissions, and are used to repair various reinforced concrete structures in sodium sulphate aggressive mediums.Alqahtani et al. [23] reported thatrecovering plastic waste would reduce the $\mathrm{CO}_{2}$ emissions by 3.8 million tons. So, these results are in agreement with those stated by these authors [23].

Finally, we can suggest the use of thesecurrent composite materials for surface treatment of building and construction façades exposed to marine environment (For example; Hassan II mosque), as well as harbour infrastructures and manufacture of waste water sewer pipes and theirs accessories (junction mortars).

\subsection{XRD analysis}

Figure 6 exhibits the XRD analysis of PET0 and PET17, after attack by $\mathrm{Na}_{2} \mathrm{SO}_{4}$ solution. The stacking of various spectraconfirms the appearance of:

- $\quad$ Ettringite $(\mathrm{E}) \mathrm{Ca}_{6} \mathrm{Al}_{2}\left(\mathrm{SO}_{4}\right)_{3}(\mathrm{OH})_{12} \cdot 26 \mathrm{H}_{2} \mathrm{O}: 9.73^{\circ} 2 \mathrm{\theta}$;

- Thaumasite $(\mathrm{T}), \mathrm{Ca}_{6}\left[\mathrm{Si}(\mathrm{OH})_{6}\right]_{2}\left(\mathrm{CO}_{3}\right)_{2}(\mathrm{SO} 4)_{2} \cdot 24 \mathrm{H}_{2} \mathrm{O}$ : $9.73^{\circ} 2 \theta$

- $\quad \operatorname{Gypsum}(\mathrm{G}) \mathrm{CaSO}_{4} \cdot 2 \mathrm{H}_{2} \mathrm{O}: 11.59^{\circ}, 20.72^{\circ}, 23.40^{\circ} 2 \Theta$

- Calcite (C), $\mathrm{CaCO}_{3}$ : from the crushed natural limestone sand $\left(29.41^{\circ} 2 \Theta\right)$;

- PortlanditeCa $(\mathrm{OH})_{2}$ was completely decomposed by $\mathrm{Na}_{2} \mathrm{SO}_{4}$ solution resulting from the chemical sulphate reactions [6]. 


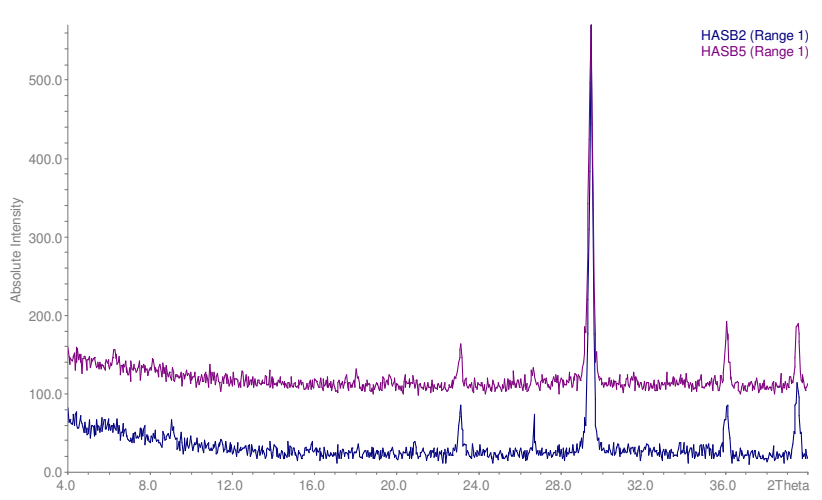

Fig. 6. X-ray diffraction pattern of the specimens under 5\% sodium sulphate attacks, after 90 days. (Blue: PET0; Pink: PET17).

\section{Conclusions}

With reference to the results presented in this paper, the main conclusions which can be drawn are summarized as follows:

- Composite modified mortars by waste PET plastics present a significant resistance to sodium sulphate attackswhich reduces the consumption energy of modified mortars resulting from PET-cement substitutes. Thecorrosion resistance coefficients decrease with exposure time to sodium sulphate aggressive medium.

- The mechanical properties of PET-mortar composites computed by ACI-318 and BS-8110 codes decrease with the increasing of PET volumetric substitution rate and this, for all studied cases (before and after immersion in $5 \%$ $\mathrm{Na}_{2} \mathrm{SO}_{4}$ medium).Prediction model proposed by BS8110 gives always the lowest values of elastic Young modulus which can be recommended for structural design in terms of safety and mechanical reliability.

- Since PET-mortar composite are resistant to sodium sulphate attack (as concluded above), the mechanical properties loss in terms of static Young modulus of elasticity $(Y M L \%)$ of modified mortars are lower than the ones of unmodified mortars (PET0). The optimal minimal values of $(Y M L \%)$ are given by ACI-318 code of practice, for the case ofPET-Modified mortars within volumetric rate of $6 \%, 12 \%$ and particularly, 17\% (PET17).

- Finally, the better durability properties of PETmortar composites observed in this study indicate longer life of the repaired structure by using this type of green PET-modified repair materials.

Acknowledgements -The authors acknowledge financial support from the Ministry of Higher Education and Scientific Research of Algeria, under the grants CNEPRU B00L01UN310120130068.
2. Saikia, N. J. de Brito, Constr. Build. Mater.34(2012).

3. R. Sharma, P.P. Bansal, J. Clean. Prod. 112(2016).

4. I.H. Alfahdawi, S.A. Osman, R. Hamid, A.I. AlHadithi, J. Eng. Sci. Technol.11,8(2016).

5. L. Gu, T. Ozbakkaloglu, Waste Manage. 51,19 (2016).

6. A.S. Benosman, H. Taïbi, M. Mouli, Performances Mécaniques et Durabilité des Composites MortierPET, Recherche et Développement dans la Revalorisation et l'Application des Déchets du PET en Génie Civil. Maison d'édition: Editions universitaires européennes, EUE (2016).

7. Benosman, A.S., Taïbi, H., Mouli, M., Senhadji Y., Belbachir M., Bahlouli I., Houivet D., J. Mater. Environ. Sci. 559 (2015).

8. S. Akcaözoğlu, CD. Atis, K. Akcaözoğlu, Waste Manage. 30, 2 (2010).

9. N. Saikia, J. de Brito, Constr. Build. Mate. 52(2014).

10. A. Sadrmomtazi, S.D. Milehsara, O.L. Omran, A.S. Nik, J. Clean. Prod. 112 (2016).

11. NFP 18-560, Granulats. Analyse Granulométrique par Tamisage, (Association française de normalisation, AFNOR, 1990).

12. A.S. Benosman, H. Taïbi, Y. Senhadji, M. Mouli, M. Belbachir, M.I. Bahlouli, RAPRA, SMITHERS, Prog. Rubber Plast. Re. J.33, 3(2017).

13. C1012-04, Standard Test Method for Length Change of Hydraulic-Cement Mortars Exposed to a Sulphate Solution, (Annual Book of ASTM Standards, ASTM, 2004).

14. PK. Mehta, J ACI,72, 40(1975).

15. H. Siad, S. Kamali-Bernard, H.A. Mesbah, G. Escadeillas, M. Mouli,H. Khelafi, Constr. Build. Mater. 47(2013).

16. ACI 318, Building Code Requirements for Structural Concrete (ACI 318-05) and Commentary (ACI 318R-05), ACI Committee 318, (American Concrete Institute, Farmington Hills, MI, 2005).

17. BS 8110. Structural use of concrete. Code of practice for design and construction. (British Standards Institution, 1997).

18. A.S. Benosman, M. Mouli, H. Taibi, M. Belbachir, Y. Senhadji, I. Bahlouli, D. Houivet, In the Proceedings of CIMDD'2013, (UniversitéBoumerdès, Algérie, 2013).

19. A. Aattache, A. Mahi, M. Mouli, A.S. Benosman, In the Proceedings of CMSS'2013, (Rabat, Morocco, 2013).

20. A. Aattache, R. Soltani, A. Mahi, Constr. Build. Mater. 146 (2017).

21. L. Jiang, Z. Liu, Y. Ye, Cem. Concr. Res. 34 (2004).

22. S. Miletić, M. Ilić, S. Otović, R. Folić, Y. Ivanov, Constr. Build. Mater.13, 3 (1999).

23. Fahad K. Alqahtani, M. Iqbal Khan, G.Ghataora,S.Dirar,J. Mater. Civ. Eng.ASCE, 29, 4(2017).

\section{References}

1. http://www.planetoscope.com/petrole/989production-mondiale-de-plastique.html 